\title{
Prevalence and Resistance Pattern of Staphylococcus aureus Isolated from a Al-Hussain Teaching Medical City, Al-Zahraa Hospital, and Obstetric Teaching Hospital in Karbala Governorate, Iraq
}

\author{
Abdul Hussain Sahib Kadhim* \\ College of Medicine, Karbala University, Iraq \\ *Corresponding author
}

\begin{tabular}{l} 
Ke y w o r d s \\
$\begin{array}{l}\text { Antimicrobial } \\
\text { susceptibility, Prevalence, } \\
\text { Antibioticresistance, } \\
\text { Staphylococcus }\end{array}$ \\
Article Info \\
$\begin{array}{l}\text { Accepted: } \\
\text { 25 April } 2018 \\
\text { Available Online: } \\
\text { 10 June } 2018\end{array}$ \\
\hline
\end{tabular}

\section{A B S T R A C T}

Staphylococcus aureus continues to be a dangerous pathogen for both community-acquired as well as hospital-associated infections. The aim of this study was to determine the prevalence and antibiotic susceptibility of $S$. aureus and Methicillin Resistant $S$. aureus (MRSA) in the environments of three hospitals in Karbala, Iraq. To study the prevalence of resistant strains of $S$. aureus isolated from the environments of three hospitals in Karbala, Iraq. A total of 200samples were collected exudative specimens such as Pus, Wound swabs, Blood, Throat swabs, and urine obtained from cultures of specimens from patients who had been hospitalized for 48 hours. The swab samples were directly plated on Mannitol Salt and Baird Parker agar plates and incubated at $37{ }^{\circ} \mathrm{C}( \pm 2)$ for 18 $24 \mathrm{~h}$. An antibiotic susceptibility test was performed using the Clinical Laboratory Standard Institute's guidelines. A total number of 200 clinical samples were processed which included 45Pus, 40 Wound swabs, 35 Blood, 30 Throat swabs, 50 Urine. Of the entire number of clinical samples processed, only 200 samples were found positive for bacterial growth. The prevalence of Staphylococcus aureus in the culture positive samples was found $44 \%$ (88). Coagulase negative staphylococci, $29.16 \%$ (7) and $62.22 \%$ (38) Gram negative bacilli. The incidence of $S$. aureus in the types of clinical samples Methicillin-resistant $S$. aureus had high prevalence among Iraqi patients which were admitted in Hospitals, which indicate their predominance in our community. Accurate and continuous surveillance of antibiotic resistance patterns among $S$. aureus strains should be considered in emergency health care centers.

\section{Introduction}

Staphylococcus aureus has long been considered as a major pathogen of hospital infections all-around the world. It has been associated with bacteremia, infective endocarditis and various types of infections including skin and soft tissue, osteoarticular, pleuropulmonary, urinary tract and device- related (Shrestha et al., 2009; Megged, 2014; Yahaghi et al., 2014). The ability of $S$. aureus to develop resistance to certain environmental conditions and also wide range of antibiotics and disinfectant agents. Bacteria have been implicated as a cause of long-term survival pathogens in the environment (Holland, 2014). Methicillin resistant S. aureus (MRSA), has emerged as a nosocomial pathogen of major 
worldwide importance and is an increasingly frequent cause of community-acquired infections that cause significant morbidity and mortality ((Rubin et al., 1999). In 1961, there were reports from the United Kingdom of S. aureus isolates, which resisted to methicillin, and MRSA isolates were soonrecovered from other European countries, and later from Japan, Australia, and the United States (CDC, 1999).

MRSA is a resistant variant of Staphylococcus aureuswhich has evolved an ability to survive treatment with beta-lactam antibiotics which includes penicillin, methicilllin and cephalosporins and to various other groups of antimicrobial agents. They are often referred to as superbugs. Most isolates remain susceptible to Glycopeptides (Vancomycin, Teicoplanin), Oxazolidinones (linezolid) Streptograminins (quinupristin-dalfopristin), and polycyclic compounds (tetracycline, tigecycline) (Moreillo et al., 2005; Deresinski, 2005). The synthesis of large numbers of antibiotics over the past three decades has caused complacency about the threat of bacterial resistance. Bacteria have become resistant to antimicrobial agents as a result of chromosomal changes or the exchange of genetic material via plasmids and transposons (Rubin et al., 1999). Resistance to antibiotics is a significant worldwide problem and antibiotic use is being recognized as the key selective force driving this resistance (Kreiswirth et al., 1993; Sehhati et al., 2009). Traditionally, MRSA was identified infrequently from patients in the community, but over the last few years reports have documented increases in community-acquired MRSA, which may suggest a changing in epidemiology (Kallen et al., 2000; Ghojazadeh et al., 2014).

In Iraq, several studies were carried out regarding the prevalence and antimicrobial resistance of MRSA from different clinical materials, but little is known about these bacteria in patients with health care centre. For that this study was designed to detect the prevalence and antimicrobial resistance pattern of MRSA isolates from Iraqi patients admitted in Al-Hussain Teaching medical city, Al-Zahraa hospital, and Obstetric teaching hospital in Karbala governorate / Iraq. The aim of this research was to study the prevalence of $S$. aureus infections in the Karbalahospitals and the drug resistance pattern in the isolates with an intension to help start the appropriate empirical antibiotic treatment of patients even on the levels of primary healthcare centers

\section{Materials and Methods}

\section{Study Design}

Staphylococcus aureus strains isolated from cultures of specimens from patients who have been hospitalized for $>48$ hours in Al-Hussain Teaching medical city, Al-Zahraa hospital, and Obstetric teaching hospitals in Karbala governorate / Iraq were included in the study.

\section{Isolation and Identification of Clinical Specimens}

The samples were collected exudative specimens such as Pus, Wound swabs, Blood, Throat swabs, and urine obtained from cultures of specimens from patients who had been hospitalized for 48 hours. Staphylococcus aureus were characterized by their morphology on Gram staining, growth characteristics and coagulase production. The study was carried out between November 2017 to December 2017.

\section{Antimicrobial Susceptibility Testing}

The antibiotic susceptibility pattern of all the confirmed $S$. aureus were determined by Kirby-Bauer disc diffusion method against the following antibiotics as per CLSI guidelines: 
Octadisc (combi 68). Cefoperazone (75 mcg), Cefpodoxime (30mcg), Ceftazidime (30 mcg), Cefepime (30mcg), Meropenem (10 mcg), Gentamicin (10 mcg), Amikacin (30 mcg) and Moxifloxacin $(5 \mathrm{mcg})$. Muller-Hinton agar used to perform all antimicrobial susceptibility tests, and the interpretation criteria were taken according to National Committee for Clinical Laboratory Standard (NCCLS).

\section{Screening for MRSA}

Methicillin resistance was screened by disc

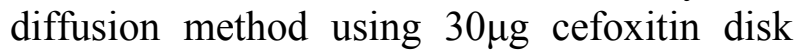
(Becton Dickinson). The diameter of the zone of inhibition was measured and interpretation was done in accordance with the CLSI guidelines.

An isolate was considered to be a MRSA strain if cefoxitin inhibition zone diameter was $<21 \mathrm{~mm}$ (CLSI, 2007). Since Staphylococcus aureus can be a colonizer (Madani, 2002; Moreillon and Glauser, 2005) special emphasis was laid on the clinical significance of all the isolates. This was done by correlating with Gram stained smear examination and ascertaining significance with the clinical history.

\section{Results and Discussion}

In this study, we describe the incidence of MRSA isolation in Al-Hussain Teaching medical city, Al-Zahraa hospital, and Obstetric teaching hospital in Karbala governorate / Iraq. We determined the MRSA incidence in our facility while generating our hospital antibiogram in support of our healthcare providers to more effectively treat their patients. Thus, we determined the baseline of MRSA prevalence to better inform incoming healthcare providers. This study represents the longest survey of MRSA incidence performed in Karbala governorate in Iraq.
A total number of 200 clinical samples were processed which included 45Pus, 40 Wound swabs, 35 Blood, 30 Throat swabs, 50 Urine. Of the entire number of clinical samples processed, only 200 samples were found positive for bacterial growth. The prevalence of Staphylococcus aureus in the culture positive samples was found $44 \%$ (88), Coagulase negative staphylococci, and $29.16 \%$ (7) and $62.22 \%$ (38) Gram negative bacilli. The incidence of $S$. aureus in the types of clinical samples is shown in Table 1.

The prevalence of MRSA and MSSA in the clinical samples has been shown in Table 2 . The prevalence of MRSA was found to be $44 \%$ (88) in the entire studied population.

$S$. aureus is a leading pathogen in hospital acquired infections (HAIs). The prevalence of $S$. aureus infections was next to the Gram negative bacterial infections, but on the top of Gram positive bacterial infections. However, as the isolated Gram negative bacterial pathogens were not identified to their genera or species level, the $S$. aureus infections may be considered the top leading among all the infections in the observed Bastar population. All the studied subjects were tribal and native of Bastar region only, and pyogenic and urogenital infections were found common in them. Unhygienic mode of living and least health awareness might be a cause of ease in acquiring infections.

Overall resistance patterns of MRSA isolates included in this study were consistent with those obtained by other Iraqi researchers (Mohammed, 2011; Al-Hassnawi et al., 2012), where the highest resistance rates were against $\beta$-lactam antibiotics, except carbapenems. Lack of control over antibiotic use in our country is the main reason for the development of increasing resistance to different antimicrobials among our clinical isolates including MRSA. 
Table.1 Prevalence of S. aureus in the culture positive clinical samples

\begin{tabular}{|l|l|l|l|l|}
\hline Sample & $\begin{array}{l}\text { Samples } \\
(\mathbf{n})\end{array}$ & S. aureus & $\begin{array}{l}\text { Coagulase Negative } \\
\text { S. aureus }\end{array}$ & $\begin{array}{l}\text { Gram negative } \\
\text { bacilli }\end{array}$ \\
\hline Pus & 45 & $24(53.33 \%)$ & $7(29.16 \%)$ & $38(62.22 \%)$ \\
\hline Wound swabs & 40 & $34(85 \%)$ & $0(0 \%)$ & $7(17.5 \%)$ \\
\hline Blood & 35 & $19(54.28 \%)$ & $11(57.89 \%)$ & $12(34.28)$ \\
\hline Throat swabs. & 30 & $14(46.66 \%)$ & $4(28.57 \%)$ & $0(0 \%)$ \\
\hline Urine & 50 & $9(18 \%)$ & $3(33.33 \%)$ & $41(82 \%)$
\end{tabular}

\section{Table.2 Prevalence of MRSA and MSSA in the clinical samples}

$\frac{\text { Total clinical samples }}{(n=200)}$

Pus (n=45)

Wound swabs $(n=40)$

$\operatorname{Blood}(\mathbf{n}=35)$

Throat swabs $(\mathrm{n}=30)$

Urine $(\mathbf{n}=\mathbf{5 0})$

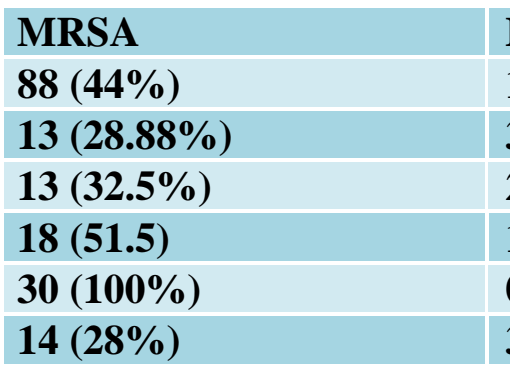

MSSA

$112(56 \%)$

$32(71.11 \%)$

$27(65.5 \%)$

$17(48.5 \%)$

0 $(\mathbf{0 \%})$

$36(72.00)$

\section{Table.3 Prevalence of MIRSA and MSSA in the clinical samples}

Total clinical samples
$(n=200)$

Pus (n=45)

Wound swabs $(\mathrm{n}=40)$

$\operatorname{Blood}(\mathrm{n}=35)$

Throat swabs $(n=30)$

Urine $(\mathbf{n}=\mathbf{5 0})$

\begin{tabular}{|l|l|}
\hline MRSA & MSSA \\
\hline $\mathbf{8 8}(\mathbf{4 4 \%})$ & $112(56 \%)$ \\
\hline $13(28.88 \%)$ & $32(\mathbf{7 1 . 1 1 \% )}$ \\
\hline $13(32.5 \%)$ & $27(65.5 \%)$ \\
\hline $18(51.5)$ & $17(48.5 \%)$ \\
\hline $\mathbf{3 0}(\mathbf{1 0 0} \%)$ & $\mathbf{0}(\mathbf{0 \%})$ \\
\hline $14(28 \%)$ & $\mathbf{3 6}(\mathbf{7 2 . 0 0})$ \\
\hline
\end{tabular}

\begin{tabular}{|c|c|c|c|c|c|c|c|c|}
\hline \multicolumn{9}{|c|}{ Table.4 Pattern of antibiotic resistance (\%) } \\
\hline $\begin{array}{c}\text { Total clinical } \\
\text { samples }(n=200)\end{array}$ & CPZ & CPD & CAZ & CPM & MRP & GEN & AK & MO \\
\hline Pus $(n=45)$ & $\begin{array}{c}23 \\
(51.11)\end{array}$ & $\begin{array}{c}20 \\
(44.44)\end{array}$ & $\begin{array}{c}40 \\
(88.88)\end{array}$ & $\begin{array}{c}42 \\
(93.33)\end{array}$ & $\begin{array}{c}33 \\
(73.33)\end{array}$ & $\begin{array}{c}25 \\
(55.55)\end{array}$ & $\begin{array}{c}18 \\
(40)\end{array}$ & $\begin{array}{c}43 \\
(95.55)\end{array}$ \\
\hline $\begin{array}{c}\text { Wound swabs } \\
(n=40)\end{array}$ & $34(85)$ & $\begin{array}{c}33 \\
(82.5)\end{array}$ & $\begin{array}{c}17 \\
(42.5)\end{array}$ & $\begin{array}{c}39 \\
(97.5)\end{array}$ & $\begin{array}{c}31 \\
(77.5)\end{array}$ & $\begin{array}{c}36 \\
(90)\end{array}$ & $\begin{array}{c}28 \\
(70)\end{array}$ & $26(65)$ \\
\hline Blood $(n=35)$ & $\begin{array}{c}31 \\
(88.57)\end{array}$ & $\begin{array}{c}15 \\
(42.85)\end{array}$ & $\begin{array}{c}19 \\
(54.28)\end{array}$ & $\begin{array}{c}22 \\
(62.85)\end{array}$ & $\begin{array}{c}26 \\
(74.28)\end{array}$ & $\begin{array}{c}27 \\
77.14\end{array}$ & $\begin{array}{c}11 \\
(31.42)\end{array}$ & $\begin{array}{c}34 \\
(37.14)\end{array}$ \\
\hline $\begin{array}{l}\text { Throat swabs } \\
\qquad(n=30)\end{array}$ & $\begin{array}{c}29 \\
(96.66)\end{array}$ & $\begin{array}{c}23 \\
(76.66)\end{array}$ & $\begin{array}{c}18 \\
(60)\end{array}$ & $\begin{array}{c}22 \\
(73.33)\end{array}$ & $\begin{array}{c}16 \\
(53.33)\end{array}$ & $\begin{array}{c}19 \\
(63.33)\end{array}$ & $\begin{array}{c}24 \\
(80)\end{array}$ & $\begin{array}{c}11 \\
(36.66)\end{array}$ \\
\hline Urine $(\mathrm{n}=50)$ & $45(90)$ & $\begin{array}{c}23 \\
(46)\end{array}$ & $\begin{array}{c}41 \\
(82)\end{array}$ & $\begin{array}{c}23 \\
(46)\end{array}$ & $\begin{array}{c}44 \\
(88)\end{array}$ & $\begin{array}{c}18 \\
(36)\end{array}$ & $\begin{array}{c}37 \\
(74)\end{array}$ & $\begin{array}{c}25 \\
(50)\end{array}$ \\
\hline Total $(n=200)$ & $\begin{array}{l}162 \\
(81)\end{array}$ & $\begin{array}{l}114 \\
(57)\end{array}$ & $\begin{array}{c}135 \\
(67.5)\end{array}$ & $\begin{array}{l}148 \\
(74)\end{array}$ & $\begin{array}{l}150 \\
(75)\end{array}$ & $\begin{array}{c}125 \\
(62.5)\end{array}$ & $\begin{array}{l}118 \\
(59)\end{array}$ & $\begin{array}{c}139 \\
(69.5)\end{array}$ \\
\hline
\end{tabular}




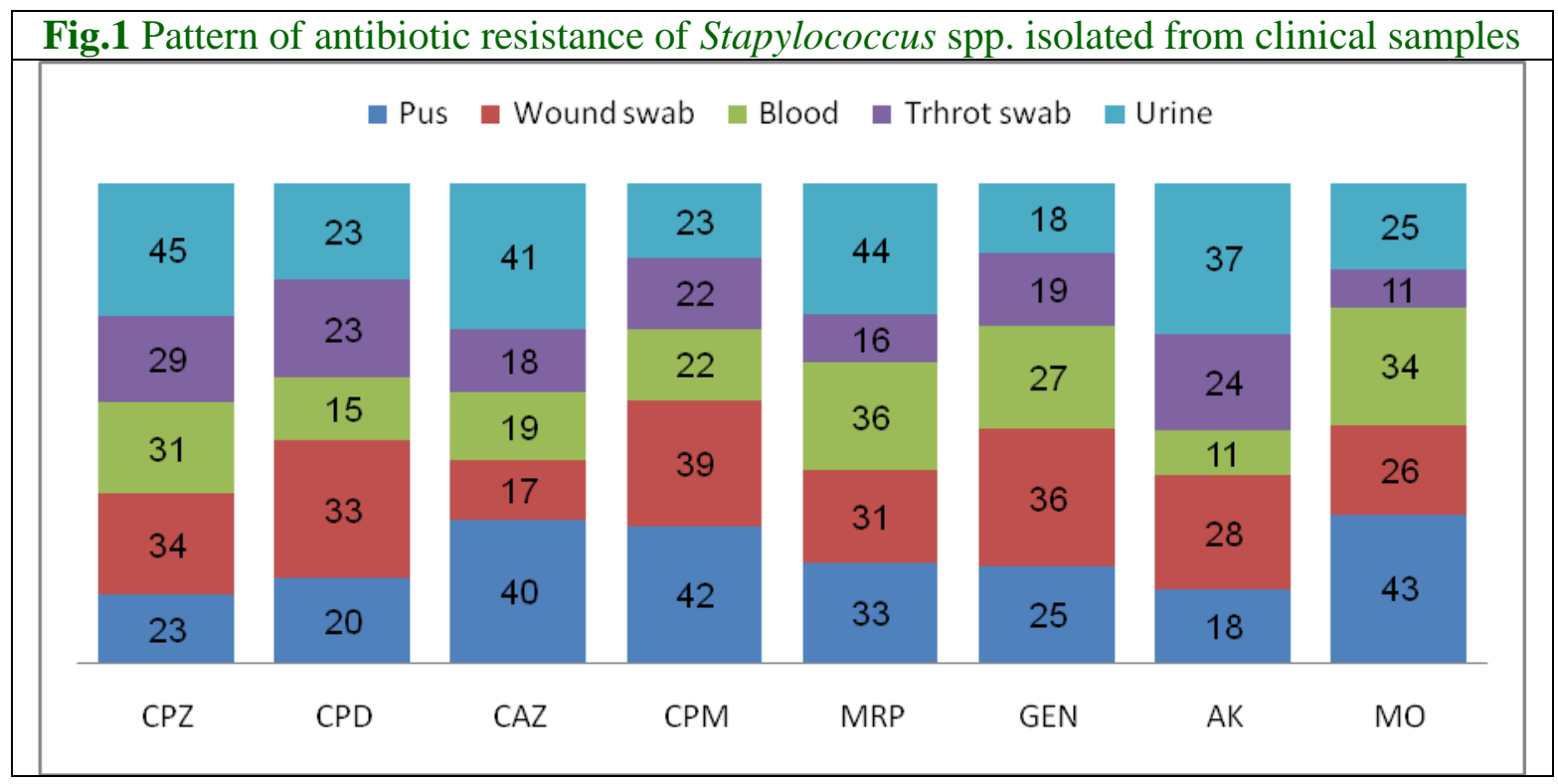

Also, overuse of $\beta$-lactams for treating different cases in our hospitals is another reason for this high prevalence of MRSA. Emergence of antibiotic-resistant bacteria clones reflects the intensive use of antimicrobial agents (Didier et al., 2011). So that there must be a scheduled rotation of $\beta$ lactams use with other antimicrobials in the study area to reduce this high antibiotic resistance among our isolates.

In a study by Alebachew et al., 2012, the $S$. aureus strains of human clinical infections were sensitive to clindamycin, vancomycin, erythromycin, and kanamycin but highly resistant to penicillin. They showed that all isolates were multi-drug resistant, and one isolates was resistant to all the tested drugs. In a research in Iran, $60 \%$ of all S.aureus isolates of hospital infections were resistant to methicillin.

Ekrami et al., 2010, showed that the highest resistance was to ciprofloxacin $(81.2 \%)$ while Momtaz and Hafezi, 2014 found that $S$. aureus isolates from hospital infections were resistant to azithromycin (62.12\%), tetracycline $(57.57 \%)$ and erythromycin (54.54\%).
Methicillin-resistant $S$. aureus had high prevalence among Iraqi patients which were admitted in Al-Hussain Teaching medical city, Al-Zahraa hospital, and Obstetric teaching hospital in Karbala governorate / Iraq, which indicate their predominance in our community. The results of the present investigation indicate that $S$. aureus might be an important causative agent of nosocomial infections in emergency centers of hospitals. Accurate and continuous surveillance of antibiotic resistance patterns among $S$. aureus strains should be considered in emergency health care centers. Effective disinfection of surfaces, beds, trolleys and surgical instruments by hospital infection control unit should be performed periodically to reduce colonization of $S$. aureus in various areas of hospital emergency wards.

\section{References}

Alebachew T, Yismaw G, Derabe A, Sisay Z. (2012). Staphylococcus aureus burn wound infection among patients attending yekatit 12 hospital burn units, addisababa, Ethiopia. Ethiop J Health Science; 22(3): 209- 213. 
Al-Hassnawi HH, Al-Charrakh AH, AlKhafaj JK (2012). Antibiotic resistance patterns of community acquired methicillin resistance Staphylococcus aureus (CA-MRSA) in Al-Hilla/ Iraq. Kerbala Journal of Pharmaceutical Sciences 10: 91-102.

Centers for Disease Control and Prevention (CDC) (1999). Four Pediatric Deaths from Community-Acquired MethicillinResistant Staphylococcus aureusMinnesota and North Dakota, 19971999. Morbidity and Mortality Weekly Report (MMWR) 1999; 48(32): 707-10.

Clinical Laboratory Standard Institute (2007). Performance standards for antimicrobial susceptibility testing; Seventeenth informational supplement-Clinical Laboratory Standard Institute M100S17; 27:1.

Deresinski S. (2005). Methicillin-resistant Staphylococcus aureus: an evolutionary, epidemiologic, and therapeutic Odyssey. Clin Infect Dis; 40:562-73.

Didier JP, Villet R, Huggler E, Lew DP, Hooper DC (2011). Impact of ciprofloxacin exposure on Staphylococcus aureus genomic alterations linked with emergence of rifampin resistance. Antimicrob Agents Chemother 55: 1848-1852.

Ekrami A, Samarbafzadeh A, Alavi M, Kalantar E, Hamzeloi F. (2010). Prevalence of methicillin resistant Staphylococcus species isolated from burn patients in a burn center, Ahvaz, Iran. Jundishapur J Microbiol; 3(2): 8491.

Ghojazadeh M, Naghavi-Behzad M, Nasrolah-Zadeh R, Bayat-Khajeh P, Piri R, and Mirnia K, (2014). Knowledge production status of Iranian researchers in the gastric cancer area: based on the medline database. Asian Pac J Cancer Prev; 15(12): 5083-8.
Holland TL, Arnold C, Fowler VG, (2014). Clinical management of Staphylococcus aureus bacteremia: a review. JAMA; 312(13): 1330-1341.

Kallen AJ, Driscoll TJ, Thornton S, Olson PE, Wallace MR. (2000). Increase in community-acquired methicillinresistant Staphylococcus aureus at a Naval Medical Center. Infect Control HospEpidemiol; 21(3): 223-6. Madani $\mathrm{T}$ A. Epidemiology and Clinical features of methicillin-resistant Staphylococcus aureus in the University Hospital, Jeddad, Saudi Arabia. Can J Infect Dis 2002; 13(4): 245-250.

Megged O. (2014). Staphylococcus aureus urinary tract infections in children are associated with urinary tract abnormalities and vesico-ureteral reflux. PediatrNephrol; 29(2): 269-272.

Mohammed SM (2011). Use of cefoxitin as indicator for detection of Methicillin Resistant Staphylococcus aureus. Baghdad Science Journal 8: 947-955.

Momtaz H, Hafezi L. (2014). Meticillinresistant Staphylococcus aureus isolated from Iranian hospitals: virulence factors and antibiotic resistance properties. Bosn J Basic Med Sci; 14(4): 219-226.

Moreillon P, Que Y A, Glauser M P. (2005). Staphylococcus aureus (including Stapylococcal toxic shock) in Mandell, Doughlas and Bennett's. Principles and practice of Infectious disease 6th ed. Churchill Livingstone; 2321-2351.

Rubin RJ, Harrington CA, Poon A, Dietrich K, Greene JA, Moiduddin A. (1999). The economic impact of Staphylococcus aureus infection in New York City hospitals. Emerg Infect Dis 1999; 5(1): 9-17.

Sehhati-Shafaii F, Asadollahy M, Piri R, Naghavi-Behzad M, Farzollahpour F. (2013) Prevalence and Risk Factors of Preterm Labor in Health Educational 
Centers of Northwest Iran. Life Sci J; 10(3): 231-236.

Shrestha B, Pokhrel B, Mohapatra T. (2009). Study of nosocomial isolates of Staphylococcus aureus with special reference to methicillin resistant $S$. aureus in a tertiary care hospital in
Nepal. Nepal Med Coll J; 11(2): 123126.

Yahaghi E, Imani Fooladi AA, Amin M, Mirnejad R, Nezamzade R, Amani J. (2014). Detection of Class I Integrons in Staphylococcus aureus isolated from Clinical Samples. Iran Red Crescent Med J.; 16(11): e16234.

\section{How to cite this article:}

Abdul Hussain Sahib Kadhim. 2018. Prevalence and Resistance Pattern of Staphylococcus aureus Isolated from a Al-Hussain Teaching Medical City, Al-Zahraa Hospital, and Obstetric Teaching Hospital in Karbala Governorate, Iraq. Int.J.Curr.Microbiol.App.Sci. 7(06): 36753681. doi: https://doi.org/10.20546/ijcmas.2018.706.431 